\title{
Significant historical changes in private practice psychiatry during the past two decades
}

Private practice psychiatry has always been strong in South Africa (SA), with important contributions to the success of private medicine. During the past two decades, however, a series of events changed the face of private psychiatry forever.

The first was the advent of so-called managed-care organisations in SA specialist medicine, of which Southern Health Care was the first to appear on the horizon. This brought a whole new way of thinking about private specialist medicine. For the first time, managed-care organisations intervened in the practice of medicine by specialists and, specifically, by psychiatrists. These interventions were obviously initially met with much resistance - private psychiatrists were certainly not used to interference in their treatment of patients.

In response to this, private psychiatrists organised themselves into a private Pty Ltd company, the Psychiatrists Management Group (PsychMG). This new concept meant that psychiatrists had to pay a monthly membership fee to a company promising to look after their best interests and to negotiate with managed healthcare organisations. Private Psychiatrists of South Africa (PPSA) employed a private company called Healthman, to offer administrative, technical and legal expertise in the management of PPSA. This was the start of a long-lasting and succesful relationship, enduring to the present day. PsychMG later amalgamated with the PPSA, a similar company started in Cape Town under the leadership of Dr Irvine Eidelman and colleagues. After a brief period of existence, PPSA became inactive, but was later resurrected when managedcare issues once again surfaced. PsychMG is currently very active, working tirelessly on behalf of all private psychiatrists in relation to the many issues threatening the private practice of psychiatry.

The fact that private psychiatrists began organising themselves into companies initiated a phase in which they became more active in SASOP. Many assumed leadership roles within the Society, such as Drs Eugene Allers and lan Westmore who were elected as SASOP presidents. Currently, the functioning of SASOP private psychiatry together with the State Employed Psychiatrists Special Interest Group (SESIG) form the two most important legs of the organisation.

The second important event which changed the face of private psychiatry, at the advent of a democratic SA, was the new government's fundamental overhaul of the private health system. This included promulgation of the National Health Reference Price List (NHRPL). Private psychiatrists were requested to perform practice costs studies - in an attempt to justify the creation of a reference price list, which would obviously include overhead costs to private practice psychiatrists. Private psychiatry was one of the first two disciplines to complete the practice costs study, and this led to a major increase in the fees that private psychiatrists could charge. This advantage endures to this day.

PsychMg was previously represented on the private practice committee of the South African Medical Association (SAMA). Over the years, private specialists became progressively disillusioned with the role and function of SAMA. Several prominent specialist groups broke away from SAMA and formed an overarching company, called the South African Private Practitioners Forum (SAPPF). Private psychiatrists continued to play a prominent role in the management of SAPPF. One of the first prominent actions of SAPPF was to issue a legal challenge to the Department of Health to challenge the NHRPL, which proved successful. Currently, no reference price list exists for private psychiatry and, for the first time, private practice psychiatrists can charge according to their own practice costs,

Planning of the national health insurance (NHI) is anticipated to pose the next big challenge for PsychMG; negotiations with government are underway to become part of this system. As yet, it is unclear what the role of private specialist medicine will be, but it is certain that private psychiatrists will be required to participate in the system.

A continuous challenge for private practice psychiatrists is to remain up-to-date with cutting-edge contemporary academic psychiatry; in this regard, PsychMG has taken it upon itself to supply continuing medical education to private practice psychiatrists. In many regards, the practice of psychiatrists is constantly monitored by external agents such as managed-care organisations; therefore, psychiatrists should be able to continually justify their actions and treatment.

The cost of private specialist medicine is continually increasing; therefore, it has become imperative that private practice psychiatrists are able to monitor the cost of treatment and continually attempt to improve treatment cost-effectiveness for all patients. The challenge, however, is not to compromise on quality and efficiency.

Challenges that have surfaced on the horizon of private psychiatry have only unified and strengthened the profession. Psychiatry has achieved full recognition as a medical discipline in its own right, playing a prominent role in medical politics. We hope, as the present leadership ages, that new young leaders will rise to the challenge and take over the torch for private psychiatry in the country.

\section{Dr Franco Colin \\ Private practice and Department of Psychiatry, University of Pretoria pfcolin@mweb.co.za}

SAfr J Psych 2012;18(3):75. DOl:10.7196/SAJP.385 